\title{
Clinical Evaluation of Total Intravenous Anesthesia Using a Combination of Propofol and Medetomidine following Anesthesia Induction with Medetomidine, Guaifenesin and Propofol for Castration in Thoroughbred Horses
}

\author{
Kazuomi OKU ${ }^{1) *}$, Masashi KAKIZAKI ${ }^{1)}$, Keiichi $\mathrm{ONO}^{1)}$ and Minoru OHTA ${ }^{1)}$ \\ ${ }^{1)}$ Racehorse Clinic, Miho Training Center, Japan Racing Association, 2500-2 Oaza-Mikoma, Mihomura, Inashiki-gun, Ibaraki 300-0439, \\ Japan
}

(Received 2 April 2011/Accepted 12 July 2011/Published online in J-STAGE 26 July 2011)

ABSTRACT. Seven Thoroughbred horses were castrated under total intravenous anesthesia (TIVA) using propofol and medetomidine. After premedication with medetomidine $(5.0 \mu \mathrm{g} / \mathrm{kg}$, intravenously), anesthesia was induced with guaifenesin $(100 \mathrm{mg} / \mathrm{kg}$, intravenously) and propofol $(3.0 \mathrm{mg} / \mathrm{kg}$, intravenously) and maintained with constant rate infusions of medetomidine $(0.05 \mu \mathrm{g} / \mathrm{kg} / \mathrm{min})$ and $\mathrm{propofol}(0.1$ $\mathrm{mg} / \mathrm{kg} / \mathrm{min}$ ). Quality of induction was judged excellent to good. Three horses showed insufficient anesthesia and received additional anesthetic. Arterial blood pressure changed within an acceptable range in all horses. Decreases in respiratory rate and hypercapnia were observed in all horses. Three horses showed apnea within a short period of time. Recovery from anesthesia was calm and smooth in all horses. The TIVA-regimen used in this study provides clinically effective anesthesia for castration in horses. However, assisted ventilation should be considered to minimize respiratory depression. KEY WORDS: equine, propofol, total intravenous anesthesia.

Propofol (2,6-diisopropylphenol) is characterized by short duration of action with little cumulative effects, easiness of anesthetic depth control and rapid recovery [14]. For this reason, it has been widely used for induction and maintenance of total intravenous anesthesia (TIVA) in humans and animals [12, 19]. Propofol is often used in combination with analgesics, sedatives or other anesthetics because of its poor analgesic properties and high cost [14]. In humans, TIVA with propofol and ketamine has become a popular means of anesthesia and has been reported to provide a good maintenance state without remarkable cardiorespiratory depression [12]. Propofol has also been used for horses as TIVA in combination with ketamine and is known to provide sufficient anesthesia [10, 20, 24, 25].

Ketamine is reported to stimulate the limbic system and frequently produce dysphoria, hallucinations, delirium, excitement and undesirable catatonic response [2], and these effects can cause accidents during recovery when sedation is insufficient. Moreover, ketamine was designated as a narcotic drug under the Narcotics and Psychotropics Control Law in Japan in January 2007, and the usage of ketamine is severely restricted. Therefore, in the equine clinical field, there is a demand for a new propofol TIVA technique without using ketamine. In place of ketamine, medetomidine, the most potent $\alpha_{2}$-agonist currently available in Japan, was selected, and guaifenesin, a central muscle relaxant, was used to supplement the poor induction of propofol. The purpose of this study was to evaluate the clinical availability of the TIVA technique with medetomidine and propofol fol-

\footnotetext{
* Correspondence to: OKu, K., Racehorse Clinic, Miho Training Center, Japan Racing Association, 2500-2 Oaza-Mikoma, Mihomura, Inashiki-Gun, Ibaraki 300-0439, Japan.

e-mail: KAZUOMI_OKU@jra.go.jp
}

lowing induction with medetomidine, guaifenesin and propofol for surgical procedures.

Seven male Thoroughbred horses were used. The horses' ages ranged from 3 to 7 years old (mean \pm standard deviation, $4.9 \pm 1.3$ years), and their weights ranged between 432 and $574 \mathrm{~kg}(503 \pm 46 \mathrm{~kg})$. The horses were considered healthy based on the results of physical, blood and electrocardiogram examination prior to surgery. They were fasted for $12 \mathrm{hr}$ before anesthesia but had free access to water. All procedures were conducted according to the guidelines established by the Experimental Animal Committee, Japan Racing Association.

Each horse was catheterized in the left jugular vein with a $14-\mathrm{G}$ catheter and premedicated with medetomidine $(5.0 \mu \mathrm{g} /$ $\mathrm{kg}$; Domitor, Orion Corporation, Espoo, Finland). Ten min after premedication, anesthesia was induced by administration of guaifenesin $(100 \mathrm{mg} / \mathrm{kg} ; 5 \%$ Guaifenesin, Shinyo Pure Chemicals Co., Ltd., Osaka, Japan) and 1\% propofol (3.0 mg/kg; Rapinovet, Mallinckrodt Veterinary, Mundelein, IL, U.S.A.). The $3.0 \mathrm{mg} / \mathrm{kg}$ of propofol was bolus injected after the onset of muscle relaxation induced by the administration of guaifenesin. During induction, the horse's head and tail were controlled with a halter and rope through a wall ring. The time taken for the horses to assume a recumbent posture from the end of propofol injection was recorded, and the quality of induction was quantified using a score of 1 to 5 (1, poor; 2, marginal; 3, fair; 4, good; 5, excellent) according to a description by Mama $[15,16]$.

After induction, the horses were intubated endotracheally and placed on a padded mattress in right lateral recumbency. The endotracheal tube was connected to a demand valve supplied with $100 \%$ oxygen, and ventilation was assisted for 1 or 2 breaths via demand valve when apnea persisted for 
more than one minute.

Anesthesia had been maintained for 50 min with propofol and medetomidine infusion using volumetric infusion pumps (IVAC 599, Alaris Medical System, San Diego, CA, U.S.A.), and surgical castration by half-closed technique was performed. Propofol and medetomidine were infused at the constant rates of $0.10 \mathrm{mg} / \mathrm{kg} / \mathrm{min}$ and $0.05 \mu \mathrm{g} / \mathrm{kg} / \mathrm{min}$, respectively. When the signs of too light anesthesia, such as nystagmus, were observed, $1.0 \mathrm{mg} / \mathrm{kg}$ of propofol was additionally bolus administered, and when gross purposeful movement was observed, $2.0 \mathrm{mg} / \mathrm{kg}$ of thiopental sodium (Ravonal, Mitsubishi Tanabe Pharma, Osaka, Japan) was also administered. Thiopental was used to immobilize horses quickly with a smaller volume of solution than propofol. The depth of anesthesia was judged based on the hemodynamic response, the degree of muscle relaxation, the rate and character of breathing and the presence or absence of the swallowing reflex, nystagmus and gross purposeful movement.

Respiratory rate (RR), heart rate (HR), arterial blood pressure and arterial partial pressures of $\mathrm{O}_{2}$ and $\mathrm{CO}_{2}\left(\mathrm{PaO}_{2}\right.$ and $\mathrm{PaCO}_{2}$ ) were measured every 10 min during maintenance of anesthesia. HR was also measured before and after premedication and just after induction. RR was also measured immediately after induction. The RR was counted by expiration through the demand valve, and HR was obtained by auscultation or electrocardiograph (base-apex lead). Arterial blood pressure was obtained using a multipurpose monitoring system (M1166A, Hewlett-Packard, Palo Alto, CA, U.S.A.) connected via a transducer with a $20-\mathrm{G}$ catheter placed in the facial artery. The zero level of the transducer was placed at the height of the sternum. $\mathrm{PaO}_{2}$ and $\mathrm{PaCO}_{2}$ were analyzed in blood samples collected from the arterial catheter using a calibrated arterial blood gas analyzer (860CO, Bayer Medical, Medford, MA, U.S.A.).

After anesthesia, horses were immediately transported to a darkened recovery room, positioned in lateral recumbency and extubated. During recovery, resedation and assistance for standing were not provided. The times from the end of anesthesia to first movement, sternal recumbency, first attempt to stand and standing up were recorded. The number of attempts to stand was also recorded, and the quality of recovery was quantified using a score of 1 to 5 in the same manner as for induction.

The data were summarized as means \pm standard devia- tion. Data sets of cardiopulmonary measurements were analyzed with repeated measure analysis of variance to determine the effects over time. When appropriate, values between different measurement time points were examined by the Student-Newman-Keuls test. The level of statistical significance was less than $0.05(P<0.05)$.

The mean time from the end of propofol injection to when the horses assumed a recumbent posture was $37.9 \pm 10.4$ sec. The induction score was 5 (excellent) in 5 horses and 4 (good) in 2 horses. In one of the horses scored as 4 (good), transient muscular rigidity appeared after propofol injection, and slight movement of the limbs was observed immediately after assuming a recumbent posture. Endotracheal intubation was easy, and no rigidity of the masseter muscle or swallowing movements was observed.

During maintenance of anesthesia, 4 horses did not show any signs of too light anesthesia. However, the remaining 3 horses showed nystagmus at $30 \mathrm{~min}$ after induction, and 1.0 $\mathrm{mg} / \mathrm{kg}$ of propofol was additionally administered. Since one horse still showed nystagmus and gross purposeful movement, $2.0 \mathrm{mg} / \mathrm{kg}$ of thiopental sodium was supplementary administered. Furthermore, this horse showed nystagmus again at $50 \mathrm{~min}$ after induction, and another $1.0 \mathrm{mg} / \mathrm{kg}$ of propofol was administered. In all horses, brisk palpebral and corneal reflexes were observed throughout the anesthetic period.

The results of the cardiovascular measurements are summarized in Table 1. HR decreased significantly after medetomidine premedication, from 41 beats $/ \mathrm{min}$ to 31 beats/min, and HR stayed significantly lower compared with the values before premedication throughout anesthesia. In addition, HR at $10 \mathrm{~min}$ after induction was significantly lower than that immediately after induction. Arterial blood pressure did not change significantly, and mean arterial blood pressure ranged between 103 and $113 \mathrm{mmHg}$ during anesthesia.

The results of the respiratory measurements are shown in Table 2 . RR decreased significantly over time during anesthesia, from $4.0 \pm 2.2$ breaths $/ \mathrm{min}$ immediately after induction to $2.3 \pm 2.1$ breaths $/ \mathrm{min}$ at $50 \mathrm{~min}$ after induction. RR at 20 and $50 \mathrm{~min}$ after induction was significantly lower than that at $10 \mathrm{~min}$ after induction. Apnea appeared between 10 and $15 \mathrm{~min}$ after induction in one horse and at approximately 35 min after induction, which was just after additional propofol bolus administration, in other 2 horses.

Table 1. Recorded cardiovascular measurements in 7 horses during medetomidine-propofol anesthesia

\begin{tabular}{|c|c|c|c|c|c|c|c|c|}
\hline \multirow{2}{*}{ Variable } & \multirow{2}{*}{$\begin{array}{l}\text { Predrug } \\
\text { value }\end{array}$} & \multirow{2}{*}{$\begin{array}{c}\text { After } \\
\text { premedication }\end{array}$} & \multirow{2}{*}{$\begin{array}{l}\text { Immediately } \\
\text { after induction }\end{array}$} & \multicolumn{5}{|c|}{ Minutes after induction } \\
\hline & & & & 10 & 20 & 30 & 40 & 50 \\
\hline HR & $41 \pm 7$ & $31 \pm 4^{\mathrm{a})}$ & $33 \pm 10^{\mathrm{a})}$ & $\left.28 \pm 6^{\mathrm{a}, \mathrm{b}}\right)$ & $26 \pm 7^{\mathrm{a})}$ & $27 \pm 9^{\text {a) }}$ & $27 \pm 8^{\text {a) }}$ & $27 \pm 8^{\text {a) }}$ \\
\hline SAP & NM & NM & NM & $132 \pm 17$ & $137 \pm 20$ & $142 \pm 25$ & $140 \pm 22$ & $136 \pm 20$ \\
\hline MAP & NM & NM & NM & $103 \pm 14$ & $106 \pm 17$ & $113 \pm 22$ & $109 \pm 20$ & $109 \pm 18$ \\
\hline DAP & NM & NM & NM & $92 \pm 15$ & $94 \pm 16$ & $100 \pm 21$ & $95 \pm 19$ & $94 \pm 20$ \\
\hline
\end{tabular}

$P<0.05$. a): Versus (Vs.) predrug value. b): Vs. immediately after induction. Data are expressed as means \pm SD. HR: heart rate (beats/min). SAP: systolic arterial pressure ( $\mathrm{mm}$ of $\mathrm{Hg}$ ). DAP: diastolic arterial pressure ( $\mathrm{mm}$ of $\mathrm{Hg}$ ). MAP: mean arterial pressure (mm of $\mathrm{Hg}$ ). $\mathrm{NM}$ : values not measured. 
Table 2. Recorded respiratory measurements in 7 horses during medetomidine-propofol anesthesia

\begin{tabular}{lcccccc}
\hline \multirow{2}{*}{ Variable } & $\begin{array}{c}\text { Immediately } \\
\text { after induction }\end{array}$ & \multicolumn{5}{c}{ Minutes after induction } \\
\cline { 3 - 7 } & \multicolumn{1}{c}{10} & 20 & 30 & 40 & 50 \\
\hline $\mathrm{RR}$ & $4.0 \pm 2.2$ & $3.7 \pm 1.6$ & $2.7 \pm 1.8^{\mathrm{a})}$ & $2.4 \pm 2.5$ & $2.6 \pm 2.8$ & $2.3 \pm 2.1^{\mathrm{a})}$ \\
$\mathrm{PaO}_{2}$ & $\mathrm{NM}$ & $351 \pm 106$ & $351 \pm 153$ & $315 \pm 157$ & $291 \pm 161^{\mathrm{b})}$ & $222 \pm 113^{\mathrm{a}-\mathrm{d})}$ \\
$\mathrm{PaCO}_{2}$ & $\mathrm{NM}$ & $60 \pm 3$ & $63 \pm 5$ & $\left.68 \pm 7^{\mathrm{a}, \mathrm{b}}\right)$ & $71 \pm 9^{\mathrm{a}, \mathrm{b})}$ & $75 \pm 4^{\mathrm{a}-\mathrm{c})}$ \\
$\mathrm{pHa}$ & $\mathrm{NM}$ & $7.312 \pm 0.033$ & $7.296 \pm 0.039$ & $7.286 \pm 0.042^{\mathrm{a})}$ & $7.273 \pm 0.043^{\mathrm{a}, \mathrm{b})}$ & $7.255 \pm 0.036^{\mathrm{a}-\mathrm{c})}$ \\
\hline
\end{tabular}

$P<0.05$. a): Versus (Vs.) $10 \mathrm{~min}$ after induction. b): Vs. $20 \mathrm{~min}$ after induction. c): Vs. $30 \mathrm{~min}$ after induction. d): Vs. 40 min after induction. Data are expressed as means $\pm \mathrm{SD}$. RR: respiration rate (breaths $/ \mathrm{min}) . \mathrm{PaCO}_{2}$ : arterial carbon dioxide tension $(\mathrm{mm}$ of $\mathrm{Hg}) . \mathrm{PaO} \mathrm{O}_{2}:$ arterial oxygen tension ( $\mathrm{mm}$ of $\mathrm{Hg}$ ). NM: values not measured.

During these apnea episodes, assisted ventilation was performed. $\mathrm{PaO}_{2}$ decreased and $\mathrm{PaCO}_{2}$ increased significantly during anesthesia in all horses.

The mean times from the end of anesthesia to first movement, sternal recumbency, first attempt to stand and standing up were $31 \pm 11,36 \pm 10,41 \pm 11$ and $44 \pm 9 \mathrm{~min}$, respectively. The recovery score was 5 (excellent) in 1 horse, 4 (good) in 1 horse and 3 (fair) in 5 horses, respectively. None of the horses became excited or struggled during the recovery period. The number of attempts to stand was once for 2 horses, twice for 3 horses, three times for 1 horse and five times for 1 horse. Ataxia was minimal, and no apparent complication was observed after anesthesia in all horses.

We previously reported the usability of the propofol-ketamine TIVA technique for prolonged anesthesia in racehorses [20]. However, for legal reasons, there is a need to establish a new propofol TIVA technique without using ketamine. Medetomidine was used as a substitute for ketamine in conjunction with propofol, since it produces potent sedation/analgesia [8] and is widely used in equine practice. Also, medetomidine is reported to be a suitable agent for prolonged use by infusion because of its pharmacokinetics [3].

Bettschart et al. reported that the combination of propofol and medetomidine was suitable for TIVA in ponies but that induction only with medetomidine and propofol leads to undesirable behavior, paddling of the limbs immediately after induction [4, 5]. In a later study, Bettschart et al. used medetomidine and ketamine for anesthetic induction of TIVA with propofol and medetomidine probably to avoid such undesirable behavior $[6,7]$. To improve the anesthetic induction quality without using ketamine, guaifenesin was used in combination with medetomidine and propofol in the present study.

Anesthetic induction with $\alpha_{2}$-agonist followed by propofol in combination with guaifenesin is reported to be smooth and excitement free in Brazilian [1] and other horses [17]. However, in the Brazilian horse study, anesthetic induction with propofol alone was also rapid and smooth, indicating the effect of guaifenesin to be ambiguous [1]. The quality of anesthetic induction with propofol is not necessarily good in Thoroughbred and other horses, and myotonus, transiently increased muscle activities and paddling immediately after assuming a recumbent posture were frequently observed even after premedication with $\alpha_{2}$-agonist $[15,16,18,20$, 21]. In this study, premedication with medetomidine was followed by guaifenesin, and after onset of muscle relaxation, propofol was bolus injected. Although transient muscular rigidity and limb movement were observed in one horse, they were slight and safe, and the quality of anesthetic induction was considered to be satisfactory. On the other hand, administration of propofol over 2 to $3 \mathrm{~min}$ is reported to produce smoother induction compared with administration over a shorter period of time $[18,20]$. However, in the present study, smooth induction was also achieved despite administration of a bolus injection of propofol. Furthermore, the time taken for the horses to assume a recumbent posture from the start of propofol injection was shorter in this study than those in the previous reports $[18,20]$. Therefore, guaifenesin is considered to be useful for making anesthetic induction with propofol rapid and smooth in Thoroughbred horses.

In the present study, the infusion rate of propofol was set at $0.1 \mathrm{mg} / \mathrm{kg} / \mathrm{min}$, which is the minimum infusion rate (MIR) for after premedication with $1.0 \mathrm{mg} / \mathrm{kg}$ of xylazine in horses [22]. MIR is the infusion rate of intravenous anesthetic preventing reaction to stimulus in $50 \%$ of population. The doses of medetomidine, $5.0 \mu \mathrm{g} / \mathrm{kg}$ for premedication and $0.05 \mu \mathrm{g} / \mathrm{kg} / \mathrm{min}$ for maintenance of anesthesia, were set a little lower than those reported in ponies by Bettschart et al., $7.0 \mu \mathrm{g} / \mathrm{kg}$ for premedication and $0.0583 \mu \mathrm{g} / \mathrm{kg} / \mathrm{min}$ for maintenance of anesthesia [3-6], in consideration of the fact that guaifenesin was used in combination with medetomidine and propofol during induction. The anesthetic depth achieved by these infusion rates was sufficient for surgical castration in 4 horses, while signs of too light anesthesia appeared in the remaining 3 horses at $30 \mathrm{~min}$ after induction. From these results, the propofol infusion rate of $0.1 \mathrm{mg} / \mathrm{kg} /$ min in combination with $0.05 \mu \mathrm{g} / \mathrm{kg} / \mathrm{min}$ medetomidine infusion was considered to be the minimum requirement to perform a surgical procedure in Thoroughbred horses. Therefore, the propofol infusion rate should be adjusted according to the individual circumstances in the case of clinical application.

The signs of too light anesthesia were observed at almost the same time, $30 \mathrm{~min}$ after induction, in 3 horses. It is reported that horses anesthetized with $1.0 \mathrm{mg} / \mathrm{kg}$ of xyla- 
zine, $20 \mu \mathrm{g} / \mathrm{kg}$ of midazolam and $3.0 \mathrm{mg} / \mathrm{kg}$ of propofol assumed sternal recumbency at $26.1 \mathrm{~min}$ and stood up at $35.3 \mathrm{~min}$ after induction [21]. Therefore, the arousal signs observed at $30 \mathrm{~min}$ after induction were considered to be caused by reduction of the anesthetic effect, which is due to the initial propofol loading dose for induction.

HR in this study decreased significantly after premedication with medetomidine and was kept significantly lower throughout anesthesia. Arterial blood pressure was lower compared with that of conscious horses [26], but it did not change significantly during anesthesia. The possible causes of the decrease in HR and arterial blood pressure include a cardiovascular depressant effect of medetomidine [26] and propofol $[14,23]$. Guaifenesin may also have contributed to the decrease in arterial blood pressure, since it is known to cause a significant decrease in arterial blood pressure without significantly changing HR and cardiac output in horses [13]. Meanwhile, the mean arterial blood pressure was maintained within the acceptable range that was higher than the value required to prevent postanesthetic complications such as myopathy (65 to $70 \mathrm{mmHg}$ or more [11]). It is suggested that medetomidine-propofol anesthesia induces comparable or less severe changes in the cardiac index than inhalation anesthesia [4]. However, further studies to reveal the cardiovascular effect are required to ascertain the safety of the anesthetic regimen.

In this study, a brief period of apnea appeared in 3 horses, and for 2 horses, the apnea was thought to have been associated with a sharp elevation of propofol blood level accompanied by additional propofol bolus administration. Propofol is a potent respiratory depressant [14]. Therefore, it would be better to adjust the propofol infusion rate accordingly based on careful anesthetic depth monitoring to prevent episodes of apnea accompanied by propofol bolus administration. Meanwhile, although RR decreased in all horses, spontaneous respiration was maintained throughout most of the period of anesthesia. TIVA with continuous infusion of propofol alone was associated with marked respiratory depression in horses [10]. The reason why spontaneous respiration remained was probably because of the dose-sparing effect of medetomidine on propofol requirement which led to less respiratory depression caused by propofol. However, $\mathrm{PaCO}_{2}$ increased from 60 to $75 \mathrm{mmHg}$ and $\mathrm{PaO}_{2}$ decreased from 350 to $220 \mathrm{mmHg}$ despite supplementation with $100 \%$ oxygen. Given this result, it is preferable to prepare a demand valve to assist ventilation in TIVA of horses with a combination of propofol and medetomidine.

The mean recovery time in this study was $44 \mathrm{~min}$ after anesthesia for $60 \mathrm{~min}$. Propofol is supposed to provide rapid and smooth recovery after anesthesia. In ponies, the mean recovery time to standing is reported to be $20.9 \mathrm{~min}$ after anesthesia for $4 \mathrm{hr}$ with 0.06 to $0.1 \mathrm{mg} / \mathrm{kg} / \mathrm{min}$ propofol and $0.0583 \mu \mathrm{g} / \mathrm{kg} / \mathrm{min}$ medetomidine infusion [5] and $38.8 \mathrm{~min}$ after anesthesia for $4 \mathrm{hr}$ with 0.07 to $0.11 \mathrm{mg} / \mathrm{kg} / \mathrm{min}$ propofol and $0.0583 \mu \mathrm{g} / \mathrm{kg} / \mathrm{min}$ medetomidine infusion [4]. Considering that the anesthesia time was shorter in this study, the recovery time was relatively longer in comparison with those in ponies. Guaifenesin, a central muscle relaxant, administered during induction in this study could have influenced the recovery time. Meanwhile, it has been suggested that the recovery time from propofol anesthesia is longer in Thoroughbred and other horses of similar weight than in ponies [24]. Therefore, in these horses, appropriate monitoring of the depth of anesthesia is crucial to prevent overdose administration of propofol, which results in the delay of recovery.

The horses were calm when standing up as in other reports [4-6], and there was no apparent complication in any horses. However, the number of attempts to stand was three or more in 2 horses and thought to be slightly greater than for other methods of TIVA using propofol in horses. This may have resulted from the administration of guaifenesin for induction. On the other hand, in the reports in which a surgical procedure was performed under TIVA with propofol, some horses required three or more attempts to stand [7, 18]. In addition, administration of morphine as a preanesthetic medication and infusion during anesthesia has been demonstrated to reduce the number of attempts to stand in horses that received surgery under halothane anesthesia, and one explanation for this is that postoperative pain stimulated return of consciousness, after which untreated pain discouraged further movement [9]. In light of these reports, many horses in this study may have tried to stand before regaining sufficient strength and coordination due to the pain stimulus caused by castration, and as a result, the number of attempts to stand may have been comparatively large. Therefore, the number of attempts to stand could have been improved by administration of an appropriate analgesic during anesthesia or recovery.

In conclusion, anesthetic induction with medetomidine and propofol in combination with guaifenesin followed by maintenance of anesthesia with medetomidine and propofol infusion provided a satisfactory quality of anesthetic induction, maintenance and recovery in horses. Therefore, this regimen was considered to be acceptable for surgical castration in Thoroughbred horses. However, since short apnea appeared during maintenance of anesthesia in some horses, preparing a device for assisted ventilation is preferable to minimize risk related to such respiratory depression. To apply this regimen in the field, where assisted ventilation devices are not available, adjustment of the propofol infusion rate accordingly based on careful monitoring of anesthetic depth is important to prevent apnea. Supplemental analgesic administration during anesthesia or recovery may aid in providing more satisfactory recovery from anesthesia.

\section{REFERENCES}

1. Aguiar, A. J. A., Hussni, C. A., Luna, S. P. L., Castro, G. B., Massone, F. and Alves, A. L. G. 1993. Propofol compared with propofol/guaiphenesin after detomidine premedication for equine surgery. J. Vet. Anaesth. 20: 26-28.

2. Benson, G. J. and Thurmon, J. C. 1990. Intravenous anesthesia. Vet. Clin. North Am. Equine Practice 6: 513-528.

3. Bettschart, W. R., Clarke, K. W., Vainio, O., Aliabadi, F. and 
Demuth, D. 1999. Pharmacokinetics of medetomidine in ponies and elaboration of a medetomidine infusion regime which provides a constant level of sedation. Res. Vet. Sci. 67: 41-46.

4. Bettschart, W. R., Bowen, M. I., Freeman, S. L., Feller, R., Bettschart, R. W., Nolan, A. and Clarke, K. W. 2001. Cardiopulmonary effects of prolonged anesthesia via propofol-medetomidine infusion in ponies. Am. J. Vet. Res. 62: 1428-1435.

5. Bettschart, W. R., Freeman, S. L., Jaggin, S. N. and Clarke, K. W. 2001. Infusion of a combination of propofol and medetomidine for long-term anesthesia in ponies. Am. J. Vet. Res. 62: 500-507.

6. Bettschart, W. R., Bowen, M. I., Freeman, S. L., Weller, R. and Clarke, K. W. 2003. Medetomidine-ketamine anaesthesia induction followed by medetomidine-propofol in ponies: infusion rates and cardiopulmonary side effects. Equine Vet. J. 35: 308-313.

7. Bettschart, W. R., Kalchofner, K., Neges, K., Kastner, S. and Furst, A. 2005. Total intravenous anaesthesia in horses using medetomidine and propofol. Vet. Anaesth. Analg. 32: 348-354.

8. Bryant, C. E., England, G. C. and Clarke, K. W. 1991. Comparison of the sedative effects of medetomidine and xylazine in horses. Vet. Rec. 129: 421-423.

9. Clark, L., Clutton, R. E., Blissitt, K. J. and Chase-Topping, M. E. 2008. The effects of morphine on the recovery of horses from halothane anaesthesia. Vet. Anaesth. Analg. 35: 22-29.

10. Flaherty, D., Reid, J., Welsh, E., Amonteiro, A. M., Lerche, P. and Nolan, A. 1997. A pharmacodynamic study of propofol or propofol and ketamine infusions in ponies undergoing surgery. Res. Vet. Sci. 62: 179-184.

11. Grandy, J. L., Steffey, E. P., Hodgson, D. S. and Woliner, M. J. 1987. Arterial hypotension and the development of postanesthetic myopathy in halothane-anesthetized horses. Am. J. Vet. Res. 48: 192-197.

12. Guit, J. B., Koning, H. M., Coster, M. L., Niemeijer, R. P. and Mackie, D. P. 1991. Ketamine as analgesic for total intravenous anaesthesia with propofol. Anaesthesia 46: 24-27.

13. Hubbell, J. A. E., Muir, W. W. and Sams, R. A. 1980. Guaifenesin: cardiopulmonary effects and plasma concentrations in horses. Am. J. Vet. Res. 41: 1751-1755.

14. Langley, M. S. and Heel, R. C. 1988. Propofol; a review of its pharmacodynamics and pharmacokinetic properties and use as an intravenous anaesthetic. Drugs 35: 334-372.
15. Mama, K. R., Steffey, E. P. and Pascoe, P. J. 1995. Evaluation of propofol as a general anesthetic for horses. Vet. Surg. 24: 188-194.

16. Mama, K. R., Steffey, E. P. and Pascoe, P. J. 1996. Evaluation of propofol for general anesthesia in premedicated horses. Am. J. Vet. Res. 57: 512-516.

17. Mama, K. R., Pascoe, P. J., Steffey, E. P. and Kollias, B. C. 1998. Comparison of two techniques for total intravenous anesthesia in horses. Am. J. Vet. Res. 59: 1292-1298.

18. Matthews, N. S., Hartsfield, S. M., Hague, B., Carroll, G. L. and Short, C. E. 1999. Detomidine-propofol anesthesia for abdominal surgery in horses. Vet. Surg. 28: 196-201.

19. Morgan, D. W. and Legge, K. 1989. Clinical evaluation of propofol as an intravenous anaesthetic agent in cats and dogs. Vet. Rec. 124: 31-33.

20. Ohta, M., Oku, K., Mukai, K., Akiyama, K. and Mizuno, Y. 2004. Propofol-ketamine anesthesia for internal fixation of fractures in racehorses. J. Vet. Med. Sci. 66: 1433-1436.

21. Oku, K., Yamanaka, T., Ashihara, N., Kawasaki, K., Mizuno, Y. and Fujinaga, T. 2003. Clinical observations during induction and recovery of xylazine-midazolam-propofol anesthesia in horses. J. Vet. Med. Sci. 65: 805-808.

22. Oku, K., Ohta, M., Yamanaka, T., Mizuno, Y. and Fujinaga, T. 2005. The minimum infusion rate (MIR) of propofol for total intravenous anesthesia after premedication with xylazine in horses. J. Vet. Med. Sci. 67: 569-575.

23. Oku, K., Ohta, M., Katoh, T., Moriyama, H., Kusano, K. and Fujinaga, T. 2006. Cardiovascular effects of continuous propofol infusion in horses. J. Vet. Med. Sci. 68: 773-778.

24. Umar, M. A., Yamashita, K., Kushiro, T. and Muir, W. W. 2006. Evaluation of total intravenous anesthesia with propofol or ketamine-medetomidine-propofol combination in horses. $J$. Am. Vet. Med. Assoc. 228: 1221-1227.

25. Umar, M. A., Yamashita, K., Kushiro, T. and Muir, W. W. 2007. Evaluation of cardiovascular effects of total intravenous anesthesia with propofol or a combination of ketaminemedetomidine-propofol in horses. Am. J. Vet. Res. 68: 121127.

26. Yamashita, K., Tsubakishita, S., Futaok, S., Ueda, I., Hamaguchi, H., Seno, T., Katoh, S., Izumisawa, Y., Kotani, T. and Muir, W. W. 2000. Cardiovascular effects of medetomidine, detomidine and xylazine in horses. J. Vet. Med. Sci. 62: 10251032 . 